\title{
3 Research Square

\section{Knowledge and Attitudes Towards Contraceptives Among Adolescents and Young Adults}

\section{Aanchal Sharma ( $\nabla$ aanchal10@gmail.com )}

Staten Island University Hospital https://orcid.org/0000-0002-9093-0513

\section{Edward McCabe}

Staten Island University Hospital

\section{Sona Jani}

Staten Island University Hospital

\section{Anthony Gonzalez}

Staten Island University Hospital

\section{Seleshi Demissie}

Staten Island University Hospital

\section{April Lee}

Staten Island University Hospital

\section{Research}

Keywords: Contraception, Reproduction, IUD, Sexual Health, Adolescent Health

Posted Date: February 13th, 2020

DOl: https://doi.org/10.21203/rs.2.23448/v1

License: (c) (i) This work is licensed under a Creative Commons Attribution 4.0 International License. Read Full License

Version of Record: A version of this preprint was published at Contraception and Reproductive Medicine on January 5th, 2021. See the published version at https://doi.org/10.1186/s40834-020-00144-3. 


\section{Abstract}

Background: Despite endorsements supporting the use of intrauterine devices (IUDs) for adolescents and young adult women (AYA), they have limited knowledge about them Male partners can influence contraceptive decisions, however their perceived knowledge about IUDs is lower than their objective knowledge. We aim to establish current AYA baseline contraceptive knowledge and attitudes so providers can better target their sexual health educational interventions.

Methods: Females and males, aged 13-23, from our suburban adolescent clinic, completed an anonymous survey that assessed their knowledge and attitudes towards methods of contraception, with an emphasis on the IUD.

Results: Completed surveys totaled 130 (99 females/31 males). Demographics: Black/African-American (31.3\%), Latino/Hispanic (30.5\%), White (17.6\%), Asian (3\%), and Other (14.5\%). 80\% of participants were sexually active. $69.5 \%$ stated they/their partner were currently using a contraceptive method; only $2.6 \%$ used IUDs. $56.6 \%$ of females and $10.1 \%$ of males had heard of IUDs. Despite this, male and female participants lacked knowledge regarding specific IUD facts. $6.4 \%$ who had used EC knew the copper IUD could be used for EC.

Conclusion: Contraceptive knowledge deficits, especially regarding the IUD, continue to exist for AYA patients. Many participants stated they required EC despite "satisfaction" with their birth control method and most were unaware that the copper IUD could be used as EC. These discrepancies highlight the importance of comprehensive contraceptive education for AYA patients. Enhanced and consistent contraceptive options counseling can help providers ensure that their AYA patients make well-informed decisions about family planning, thus improving their quality of life.

\section{Introduction/background}

The American College of Obstetrics and Gynecology (ACOG) has recommended intrauterine devices (IUDs) as first-line contraceptive choices for parous and nulliparous adolescents (1). The American Academy of Pediatrics (AAP) endorses the use of IUDs as contraception to parous adolescents and those who consistently protect themselves against sexually transmitted infections (2). IUD use has increased over the past decade; however, overall U.S. IUD use remains low $(3,4,5)$. Copper IUDs can also function as emergency contraception (EC), yet its use remains limited (6). Existing research has revealed that young women have limited knowledge about and access to IUDs (7). Despite its effectiveness, overall use of IUDs in the United States remains low. Only $12 \%$ of current contraceptive users reported long-acting reversible contraception (LARC) use between 2011-2013 (8,9). Studies have explored the reasons for the continued low rate of use and insertion of the IUD in adolescents and young adults despite the recognition that the IUD is a safe and effective contraceptive method $(10,11)$.

Whitaker et al. found that $40 \%$ of 144 female participants aged 14-24 had heard about IUDs; once educated, they began to think positively about IUDs (7). However, awareness is not enough. In a 2012 
study done by Barrett et al., they found that only $39.4 \%$ of subjects who had heard about the IUD were able to identify its features (12). Awareness and perceived knowledge of IUDs among males is low in comparison to condoms and birth control pills (12). Since male partners can influence the contraceptive decision-making process, it is important that studies are done to understand their perspectives.

This study aims to understand baseline contraceptive knowledge and attitudes of adolescents. This understanding will help healthcare providers improve sexual health education and overcome barriers faced by patients when choosing contraceptives methods that are best suited for them.

\section{Methods}

Subjects were recruited at Staten Island University Hospital's adolescent clinic. Participants completed a twenty-minute anonymous survey that assessed their knowledge and overall attitudes towards different methods of contraception, with an emphasis on the IUD. The survey included questions regarding age, gender, educational level, race/ethnicity, health insurance status, sexual history, sexually transmitted infection history, pregnancy history, contraception use and history of emergency contraception use. Participants were males and females, aged 13 years old to 23 years old. A total of 131 participants were offered the survey; 130 participants were accepted for the study and completed the survey.

The study design received Northwell Health Institutional Review Board approval prior to implementation. Participants provided verbal informed consent. Data was stored in a password-protected network drive. Only investigators listed on this study had access to the data.

\section{Statistical Analysis}

Demographic and clinical characteristics for the study population were summarized using means with standard deviations for continuous variables and frequencies with percentages for categorical variables. Differences between groups in continuous variables were estimated with independent-sample $t$ test. For categorical variables, Chi-square test or Fisher's exact test was used as appropriate. All tests were twotailed and Differences were considered significant at $P<0.05$. All statistical analyses were performed using SAS software (Statistical Analysis Systems Inc., Cary, NC, USA) Version 9.3.

\section{Results}

Completed surveys totaled 130. There were 99 female participants $(76.2 \%)$ and 31 male participants (23.8\%). The mean age of participants was 18.3 years old. $34.7 \%$ of respondents were aged $13-17$ and $65.3 \%$ of respondents were aged $18-23$. A majority of respondents were either in high school $(38.5 \%)$ or college (44.3\%). $18.1 \%$ identified as White, $32.3 \%$ as Black or African-American, $31.5 \%$ as Latino or Hispanic, $3.2 \%$ as Asian, and $15.0 \%$ as Other. A majority of respondents had health insurance, either private $(25.6 \%)$ or public $(40.2 \%)$. 
$80 \%$ of participants were sexually active, $14.1 \%$ with partners of the same sex, $82.8 \%$ with partners of the opposite sex, and $3.0 \%$ with both partners of the same and opposite sex. $69.5 \%$ stated they or their partner were currently using a contraceptive method. Of those using birth control, $71 \%$ used condoms, $38 \%$ used oral contraception pills (OCP), while only $2.6 \%$ used IUDs. $36.4 \%$ of total respondents reported a history of EC use by them or their partner(s). $90.5 \%$ of total respondents reported no history of STIs and $90.4 \%$ reported no history of pregnancies in themselves or their partner(s).

Majority of the participants surveyed were aware of contraceptive methods. $100 \%$ were aware of male condoms; $89.9 \%$ were aware of female condoms; $92.2 \%$ were aware of OCPs; $66.7 \%$ were aware of IUDs; 63.3\% were aware of hormonal implants; $76.2 \%$ were aware of injectable contraceptive hormones; $72.1 \%$ were aware of hormonal vaginal rings; and $64.8 \%$ were aware of hormonal contraceptive patches. Of those who responded that they had heard of the IUD, $84.9 \%$ were females and only $15.1 \%$ were males [Table 1]. Of the participants who responded that they had heard of the IUD, $90.7 \%$ were sexually active, $72.1 \%$ stated that they themselves or their partner(s) were using a form of contraception, and $49.4 \%$ stated they or their partner(s) had used EC in the past $(p<0.001)$ [Table 1].

$49.2 \%$ of participants who responded that they were satisfied with their method of birth control had used $E C$ in the past $(p<0.001)$ [Table 2]. Of those with a history of EC use by themselves or their partner(s), $83.0 \%$ reported that they or their partner(s) were using a method of birth control $(p<0.001)$ [Table 3]. Only $17.8 \%$ who reported a history of EC use knew the copper IUD could be used for EC $(p<0.001)$ [Table 3].

The awareness of the IUD was also specifically assessed by gender, sexual history, birth control use, and EC use. Of those who had heard of the IUD, $90.7 \%$ reported history of sexual activity and $49.4 \%$ reported history of EC use by them or their partner(s) ( $p<0.001)$ [Table 2]. Despite having heard of IUDs, both male and female participants lacked knowledge regarding the utility of the IUD, whether or not they were sexually active. [Table 4] Only $14.1 \%$ of those who had heard of the IUD knew that it could be used as EC $(p<0.001)$ [Table 4].

Participants were provided with an educational piece at the end of the survey, which stated: "The Intrauterine Device (IUD) is a small T-shaped device about 1 inch long. It is a very effective method of birth control that your health care provider inserts into the uterus. Non-hormonal (copper) and hormonal versions are available. The non-hormonal or copper version can be left in place for up to 10 years. The hormonal version can be left in place for up to 3 to 5 years." They were subsequently asked if they would use and/or recommend the IUD as a form of birth control. Approximately half of the participants remained neutral despite receiving the education and some provided feedback on their decisions. Some participants listed common misconceptions as their reasons against choosing the IUD in their comment section of the survey. Some participants commented that they still did not have enough knowledge regarding the IUD in general and expressed reluctance to use it or recommend to others.

Participants were also provided with information regarding the copper IUD's function as form of EC. The statement "Studies have shown that the copper IUD is the most effective form of emergency contraception" was provided to the participants. They were subsequently asked if they would use or 
recommend the copper IUD as a form of EC. Almost half of the participants remained neutral despite receiving this information and some provided feedback on their decisions. The provided feedback did reveal that some participants did feel like the copper IUD would be a good option for EC after reading the information about the efficacy of the copper IUD.

\section{Discussion}

The results of this study showed that the knowledge base of participants in this study was significantly lacking. When participants were asked about specific IUD contraceptive information, a majority of respondents answered with "I don't know". This indicated a gap in the information being presented to this population. Though many claim awareness of the IUD, they failed to understand its function or its side effects. The results of this study were similar to the 2015 study performed by Marshall et al., which found that awareness and perceived knowledge of IUDs among males was low in comparison to condoms and birth control pills (12). However, the same study has also shown that young men's perceived knowledge of IUDs was lower than their objective knowledge, whereas this study revealed that most males did not know much about the utility of the IUD (12).

Our results revealing only $2.6 \%$ of our participants using IUDs mirrored previous studies that demonstrated the low utilization of IUDs in the United States $(3,4,5)$. All of the study participants who had a history of EC use had used emergency contraception in the oral pill formulation. This was consistent with previous studies that have shown that the use of the copper IUD as EC remained limited (6).

Most participants remained "neutral" after reviewing an education section of the survey on the efficacy of the copper IUD as a contraceptive method. However, the positive responses to the education section of the survey on the efficacy of the copper IUD as a good EC option confirmed the importance of distributing factual written information to adolescents and young adults in order to expand knowledge. Provision of written information should create an opportunity to facilitate this reproductive health decision-making process by stimulating a discussion with their health care provider or health educator.

Our study was not without limitations. One limitation of this study was the small participant size. Our study population was also primarily of one geographical region located in a greater urban community. With a larger and more diverse study population, we might determine other factors involved in the reproductive health decision-making process.

\section{Conclusion}

Barriers continue to exist for adolescents and young adults when it comes to contraception - these include, but are not limited to: access, awareness, and knowledge. The IUD remains the first-line contraceptive method offered as recommended by ACOG and AAP. This study shows that despite awareness about the IUD, adequate knowledge is lacking among adolescents and young adults regarding its utility. The results of this study highlight the need for comprehensive education initiatives. For 
example, a significant percentage of participants were unaware that the IUD could also be used as a form of EC. Efficacy should play a role in satisfaction with one's birth control; however, if EC is being accessed, the birth control method may be clearly ineffective. The results of this study highlight the importance of further comprehensive contraceptive education for adolescent and young adult patients. Future research should include an assessment of the sources of information used by adolescents and young adults to attain their contraceptive knowledge as well as whether or not they received sexual health education as part of their school curricula. Enhanced contraceptive options counseling can help providers ensure that their patients make well-informed decisions about contraceptive methods, thus improving their quality of life.

\section{Abbreviations}

AAP

American Academy of Pediatrics

ACOG

American College of Obstetrics and Gynecology

AYA

adolescents and young adults

EC

emergency contraception

IUD

intrauterine device

OCP

oral contraception pill(s)

\section{Declarations}

- Ethics approval and consent to participants: The study design received Northwell Health Institutional Review Board (IRB) approval prior to implementation. IRB \#: 17-0802

- Consent for publications: Not applicable

- Availability of data and materials: The datasets during and/or analyzed during the current study available from the corresponding author on reasonable request.

- Competing interests: The authors declare that they have no competing interests.

- Funding: No funding was received.

- Authors' contributions: AS, AL, and EM were responsible for data collection and analyzed and interpreted the patient data. SJ assisted in data collection. SD performed the statistical analysis. All authors were involved in the conceptualization of this study. All authors read and approved the final manuscript.

- Acknowledgements: Not applicable 


\section{References}

1. ACOG Committee Opinion No. 392, December 2007. Intrauterine device and adolescents. Obstet Gynecol, 110, 1493-5.

2. Blythe MJ, Diaz A. Contraception and adolescents. (2007) Pediatrics, 120, 1135-48.

3. Alton, T. M., Brock, G. N., Yang, D., Wilking, D. A., Hertweck, P., \& Loveless, M. B. (2012). Retrospective Review of Intrauterine Device in Adolescent and Young Women. Journal of Pediatric and Adolescent Gynecology, 25, 195-200.

4. Mestad, R., Securar, G., Allsworth, J. E., Madden, T., Zhao, Q., \& Peipert, J. F. (2011). Acceptance of long-acting reversible contraceptive methods by adolescent participants in the Contraceptive CHOICE project. Contraception, 84, 493-498.

5. Godfrey, E. M., Memmel, L. M., Neustadt, A., Shah, M., Nicosia, A., Moorthie, M., \& Gilliam, M. (2010). Intrauterine contraception for adolescents aged 14-18 years: a multicenter randomized pilot study of Levonorgestrel-releasing intrauterine system compared to the Copper T380A. Contraception, 81, 123127.

6. Seetharaman S, Yen S, Ammerman SD. Improving adolescent knowledge of emergency contraception: challenges and solutions. Open Access Journal of Contraception. 2016;7:161-173. doi:10.2147/OAJC.S97075.

7. Whitaker AK, Johnson LM, Harwood B, Chiappetta L, Creinin MD, Gold MA. Adolescent and young adult women's knowledge of and attitudes toward the intrauterine device. Contraception. 2008;78(3):211-217

8. Daniels $\mathrm{K}$ et al. Current contraceptive use and variation by selected characteristics among women aged 15-44: United States, 2011-2013, National Health Statistics Reports, 2015, No. 86.

9. Lindberg L, Santelli $J$ and Desai S, Understanding the decline in adolescent fertility in the United States, 2007-2012, Journal of Adolescent Health, 2016, http://dx.doi.org/10.1016/j.jadohealth.2016.06.024.

10. Higgins J.A. (2017). Pregnancy ambivalence and long-acting reversible contraceptive (LARC) use among young adult women: a qualitative study. Perspectives on Sexual and Reproductive Health, 49(3):TK

11. Frost JJ, Lindberg LD and Finer LB, Young adults' contraceptive knowledge, norms and attitudes: associations with risk of unintended pregnancy, Perspectives on Sexual and Reproductive Health, 2012, 44(2):107-116

12. Marshall CJ, Gomez AM. Young men's awareness and knowledge of intrauterine devices in the United States. Contraception. 2015;92(5):494-500.

13. Deans, E. I., Grimes, D.A. (2009). Intrauterine devices for adolescents: a systematic review. Contraception, 79, 418-423.

14. Mollen, C. J., Miller, M. K., Hayes, K. L., \& Barg, F. K. (2013). Knowledge, Attitudes and Beliefs about Emergency Contraception. A Survey of Female Adolescents Seeking Care in the Emergency 
Department. Pediatric Emergency Care, 29(4), 469-474.

15. Wilkinson, T. A., Vargas, G., Fahey, N., Suther, E., \& Silverstein, M. (2014). "I'Il See What I Can Do": What Adolescents Experience When Requesting Emergency Contraception. Journal of Adolescent Health, 54, 14-19.

16. Marshall C.J., Gomez, A.M. (2015). Young men's awareness and knowledge of intrauterine devices in the United States. Contraception, 92(5), 494 - 500.

17. Association of Reproductive Health Professionals. Providers' Prospectives: Perceived Barriers to Contraceptive Use in Youth and Young Adults. Webpage accessed at http://www.arhp.org/publications-and-resources/studies-and-surveys/providers-prospectivesperceived-barriers-to-contraceptive-use-in-youth-and-young-adults, on September 26, 2017.

18. Chernick L, Schnall R, et al. Barriers to and Enablers of Contraceptive Use among Adolescent Females and their Interest in an Emergency Department-based Intervention, Contraception, 2015 Mar, 91 (3): 217 - 225. doi 10.1016/j.contraception.2014.12.00

19. Barrett M, Soon R, Whitaker AK, Takekawa S, Kaneshiro B. Awareness and knowledge of the intrauterine device in adolescents. J Pediatr Adolesc Gynecol. 2012;25(1):39-42.

\section{Tables}

Table 1: Demographics by Awareness of IUDs ${ }^{\text {[1] }}$

\begin{tabular}{|l|c|c|c|}
\hline \multirow{2}{*}{} & \multicolumn{2}{|c|}{ Have you heard of the IUD? } & \multirow{2}{*}{ P value } \\
\cline { 2 - 3 } & $\begin{array}{c}\text { Yes } \\
(\mathrm{n}=86)\end{array}$ & $\begin{array}{c}\text { No } \\
(\mathrm{n}=43)\end{array}$ & \\
\hline Gender & $73(84.9)$ & $25(58.1)$ & \\
Female & $13(15.1)$ & $18(41.8)$ & \\
Male & & & \multirow{2}{*}{$<0.002$} \\
\hline Sexual History & $78(90.7)$ & $26(60.5)$ & \\
Sexually Active & $8(9.3)$ & $17(39.5)$ & \\
Never Sexually Active & & & $<0.001$ \\
\hline Birth Control Use (self or partner) & $62(72.1)$ & $13(30.2)$ & \\
Yes & $24(27.9)$ & $30(60.8)$ & \\
No & & & $<0.001$ \\
\hline EC Use (self or partner) & $42(49.4)$ & $5(11.9)$ & \\
Yes & $43(50.6)$ & $37(88.1)$ & \\
No & &
\end{tabular}

[1]

The results reported are frequency counts with percentages in parenthesis.

Table 2: Satisfaction with Birth Control and Emergency Contraception (EC) Use ${ }^{\text {[2] }}$

\begin{tabular}{|l|c|c|c|c|}
\hline \multirow{2}{*}{} & \multicolumn{3}{|c|}{ Satisfaction with Birth Control } & \multirow{2}{*}{ P value } \\
\cline { 2 - 4 } & $\begin{array}{c}\text { Yes } \\
(\mathrm{n}=59)\end{array}$ & $\begin{array}{c}\text { No } \\
(\mathrm{n}=8)\end{array}$ & $\begin{array}{c}\text { I am not using birth control } \\
(\mathrm{n}=61)\end{array}$ & \\
\hline $\begin{array}{c}\text { History of EC Use (self or partner) } \\
\text { Yes }\end{array}$ & $29(49.2)$ & $\begin{array}{c}6(75.0) \\
2(25.0)\end{array}$ & $\begin{array}{c}11(18.0) \\
50(82.0)\end{array}$ & $<0.001$ \\
No & $30(50.8)$ & 20 \\
\hline
\end{tabular}


2 The results reported are frequency counts with percentages in parenthesis.

Table 3: History of Emergency Contraception (EC) Use ${ }^{\text {[3] }}$

\begin{tabular}{|l|c|c|c|}
\hline \multirow{2}{*}{} & History of EC Use (self or partner) & \multirow{2}{*}{ P value } \\
\cline { 2 - 3 } & $\begin{array}{c}\text { Yes } \\
(\mathrm{n}=47)\end{array}$ & $\begin{array}{c}\text { No } \\
(\mathrm{n}=82)\end{array}$ & \\
\hline Birth Control Use (self or partner) & & $36(43.9)$ & $<0.001$ \\
Yes & $39(83.0)$ & $46(56.1)$ & \\
No & $8(17.0)$ & & \multirow{2}{*}{0.001} \\
Knowledge that Copper IUD can be used as EC & & $8(10.0)$ & \\
Yes & $8(17.8)$ & $72(90.0)$ & \\
No & $37(82.1)$ & & \\
\hline
\end{tabular}

[3]

The results reported are frequency counts with percentages in parenthesis.

Table 4: Awareness vs. Knowledge Assessment of Utility of IUDs [4] 


\begin{tabular}{|c|c|c|c|}
\hline & \multicolumn{2}{|c|}{ Have you heard of the intrauterine device (IUD)? } & \multirow[t]{2}{*}{ P Value } \\
\hline & $\begin{array}{c}\text { Yes } \\
(\mathrm{n}=86)\end{array}$ & $\begin{array}{c}\text { No } \\
(n=40)\end{array}$ & \\
\hline $\begin{array}{l}\text { The copper IUD is inserted into the uterus. } \\
\text { True } \\
\text { False } \\
\text { I don't know. }\end{array}$ & $\begin{array}{c}51(59.3) \\
3(3.5) \\
32(37.2)\end{array}$ & $\begin{array}{c}6(15.0) \\
0(0) \\
34(85.0)\end{array}$ & $<0.001$ \\
\hline $\begin{array}{l}\text { Insertion of the copper IUD can cause cramping. } \\
\qquad \begin{array}{c}\text { True } \\
\text { False } \\
\text { I don't know. }\end{array}\end{array}$ & $\begin{array}{c}35(41.2) \\
4(4.7) \\
46(54.1)\end{array}$ & $\begin{array}{c}3(7.5) \\
1(2.5) \\
36(90.0)\end{array}$ & $<0.001$ \\
\hline $\begin{array}{l}\text { The copper IUD prevents pregnancy when used appropriately. } \\
\qquad \begin{array}{c}\text { True } \\
\text { False } \\
\text { I don't know. }\end{array}\end{array}$ & $\begin{aligned} 62 & (72.9) \\
2 & (2.4) \\
21 & (24.7)\end{aligned}$ & $\begin{array}{c}6(15.0) \\
2(5.0) \\
32(80.0)\end{array}$ & $<0.001$ \\
\hline $\begin{array}{l}\text { e copper IUD does not protect against sexually transmitted diseases. } \\
\qquad \begin{array}{c}\text { True } \\
\text { False } \\
\text { I don't know. }\end{array}\end{array}$ & $\begin{aligned} 52 & (61.2) \\
5 & (5.9) \\
28 & (32.9)\end{aligned}$ & $\begin{array}{c}5(12.5) \\
2(5.0) \\
33(82.5)\end{array}$ & $<0.001$ \\
\hline $\begin{array}{l}\text { Irregular Bleeding is a side effect of the copper IUD } \\
\text { True } \\
\text { False } \\
\text { I don't know. }\end{array}$ & $\begin{aligned} 37 & (44.1) \\
2 & (2.4) \\
45 & (53.5)\end{aligned}$ & $\begin{array}{c}3(7.5) \\
2(5.0) \\
35(87.5)\end{array}$ & $<0.001$ \\
\hline $\begin{array}{l}\text { The copper IUD can be used as a method of EC. } \\
\text { True } \\
\text { False } \\
\text { I don't know. }\end{array}$ & $\begin{array}{l}12(14.1) \\
35(41.2) \\
38(44.7)\end{array}$ & $\begin{array}{c}4(10.0) \\
2(5.0) \\
34(85.0)\end{array}$ & $<0.001$ \\
\hline $\begin{array}{l}\text { You can use the copper IUD even if you've never had a baby. } \\
\text { True } \\
\text { False } \\
\text { I don't know. }\end{array}$ & $\begin{array}{c}50(59.5) \\
3(3.6) \\
31(36.9)\end{array}$ & $\begin{array}{c}3(7.5) \\
1(2.5) \\
36(90.0)\end{array}$ & $<0.001$ \\
\hline $\begin{array}{l}\text { The copper IUD does not require daily reminders. } \\
\text { True } \\
\text { False } \\
\text { I don't know. }\end{array}$ & $\begin{array}{c}52(61.2) \\
4(4.7) \\
29(34.1)\end{array}$ & $\begin{array}{c}5(12.5) \\
0(0) \\
35(87.5)\end{array}$ & $<0.001$ \\
\hline
\end{tabular}

[4]

The results reported are frequency counts with percentages in parenthesis. 